\title{
Ética e economia à luz de riquezas e vulnerabilidades
}

\author{
Ethics and economics in light of wealth and vulnerabilities \\ Ética y economía a la luz de la riqueza y las vulnerabilidades
}

\section{Resumo}

O presente artigo propõe-se a refletir sobre o agir humano enquanto unicidade que promove desenvolvimento sustentável em perspectiva do progresso participativo e compartilhado. Neste sentido, a indagação que norteia a reflexão é: porque a ética e a economia se distanciaram de tal forma que há uma economia sem ética e uma ética sem economia? A pesquisa tem como objetivo descrever o agir humano enquanto a práxis necessária para a sustentabilidade. Quanto à metodologia, a pesquisa é exploratória e analítica, com abordagem qualitativa e foi realizada realizada por meio de revisão de literatura a partir do método dedutivo. Conclui-se que é preciso que a práxis seja pautada em perspectiva à uma economia ética, que dê sustentabilidade à dignidade humana, para que isso ocorra é necessário superar a dicotomia e o maniqueísmo que relativiza a unidade de desenvolvimento sustentável, participativo, compartilhado e integral. A distribuição de renda contribui para atenuar cenários de fome e abandono, todavia, é preciso adotar processos de subsidiariedade e de solidariedade, orientados à formação do bem comum, de forma a mitigar cenários de vulnerabilização.

Palavras-chave: Sustentabilidade; Economia; Ética; Economicidade; Sociabilidade.

\begin{abstract}
This article proposes to reflect on human action as a uniqueness that promotes sustainable development in the perspective of participatory and shared progress. In this sense, the question that guides the reflection is: why ethics and economics have distanced themselves in such a way that there is an economy without ethics and an ethics without economics? The research aims to describe human action as the necessary praxis for sustainability. As for the methodology, the research is exploratory and analytical, with a qualitative approach and was carried out through a literature review using the deductive method. It is concluded that it is necessary that the praxis be guided in the perspective of an ethical economy, which gives sustainability to human dignity, for this to occur, it is necessary to overcome the dichotomy and the Manichaeism that relativizes the unit of sustainable, participatory, shared and integral development. Income distribution helps to mitigate hunger and abandonment scenarios, however, it is necessary to adopt subsidiarity and solidarity processes, oriented to the formation of the common good, in order to mitigate vulnerability scenarios.

Keywords: Sustainability; Economy; Ethic; Economics; Sociability.
\end{abstract}

${ }^{1}$ PIBIC-UNIR - PVC419-2021 - Transferência de renda como inclusão: Análise sobre vulnerabilidade e direitos humanos. Edital No 2021/PIBIC/DPESQ/PROPESQ/2021 


\begin{abstract}
Resumen
Este artículo propone reflexionar sobre la acción humana como singularidad que promueve el desarrollo sostenible en la perspectiva del progreso participativo y compartido. En ese sentido, la pregunta que guía la reflexión es: ¿por qué la ética y la economía se han distanciado de tal manera que hay una economía sin ética y una ética sin economía? La investigación tiene como objetivo describir la acción humana como la praxis necesaria para la sostenibilidad. En cuanto a la metodología, la investigación es exploratoria y analítica, con un enfoque cualitativo y se llevó a cabo a través de una revisión de literatura utilizando el método deductivo. Se concluye que es necesario que la praxis se guíe en la perspectiva de una economía ética, que dé sustentabilidad a la dignidad humana, para que esto ocurra, es necesario superar la dicotomía y el maniqueísmo que relativiza la unidad de la sustentabilidad, la participación, desarrollo compartido e integral. La distribución del ingreso ayuda a mitigar escenarios de hambre y abandono, sin embargo, es necesario adoptar procesos de subsidiariedad y solidaridad, orientados a la formación del bien común, para mitigar escenarios de vulnerabilidad.
\end{abstract}

Palabras clave: Sustentabilidad; Economía; Principio moral; Ciencias económicas; Sociabilidad.

\title{
1. Introdução
}

Fomentar a discussão acerca do agir humano enquanto fonte de economicidade e de eticidade, refletindo sobre a dicotomia dos aspectos que envolvem a ética e a economia é necessário para que se possa compreender a própria pessoa humana, suas atitudes e as práxis que se apresentam como forma de sobrevivência. O ser humano é convidado à profunda reflexão sobre como viver! E o porquê viver da forma como vivemos! Reflexões desta natureza não podem se tornar abstratas à forma como as ciências humanas se desenvolvem.

A economia foi definida de diversas formas ao longo de seu processo de maturação como ciência social, mas em quase todas essas ocasiões ela foi abordada como um ramo do conhecimento que estuda a maneira como os humanos administram os limitados e escassos recursos de que dispõem para a produção de bens e mercadorias, bem como para a logística em benefício das necessidades humanas ilimitadas. Neste cenário é preciso apontar que "é preciso admitir desde já que direitos morais ou liberdade não são, de fato, conceitos aos quais a moderna economia dá muita atenção” (Sen, 1999, p. 87).

Ao passo que a ética avalia os comportamentos humanos em face dos fins, valores e princípios que condicionam as ações. O pensamento ético é uma busca pela virtude, pelo verdadeiro significado do bom, belo e verdadeiro, movendo-se à construção da felicidade coletiva. Diante disso, relevantes debates éticos envoltos em torno das propostas econômicas que são ou possam ser adotadas na árdua tarefa de gerenciar esses dados contrapostos - limitação dos recursos e ilimitadas necessidades humanas - prescrevem caminhos mais afinados com os ideários de justiça social consubstanciados na felicidade, liberdade e realização de todos.

Para aprofundar sobre a relação entre as questões econômicas e éticas salienta-se que a economia foi estudada nas disciplinas de filosofia moral e teologia até o século XVIII, sendo altamente influenciada pelo pensamento ético aristotélica e pelo pensamento platônico e, portanto, carregava em si as considerações de busca pela virtude como fator essencial para o bem comum e tinha também como finalidade se colocar a serviço da felicidade humana. No entanto, sob o imperativo das sociedades modernas a humanidade experimenta um afastamento entre ética e economia na busca pela eficiência e acúmulo de riquezas. Destaca-se que esse é um importante período em que as ciências adquirem autonomia e especialização entre si, no entanto, como tem efeito colateral a ética é afastada dos domínios dos estudos econômicos.

É nessa senda que o economista Amartya Sen (2010) propõe um movimento que reúna a busca do bem-estar humano, a responsabilidade, os interesses econômicos e a ética. Nessa empreitada se destaca que o desenvolvimento deve ser encarado não mais como o mero progresso dos marcadores econômicos, mas, antes disso, é necessário que seja promovido a ampliação das liberdades substantivas humanas já que essas são os fins do desenvolvimento.

Abordar o cenário com base nas dicotomias econômicas à luz das realizações e resultados sociais se justifica em face ao descompasso do agir humano, que gera o distanciamento que se instala entre progresso econômico e os marcadores da 
qualidade de vida das pessoas. A opulência econômica e o vertiginoso progresso tecnológico no mundo devem significar ampliação das liberdades humanas, mas a fome e a pobreza demonstram que, por si só, não são capazes de promover o desenvolvimento integral da humanidade, a riqueza gera, portanto, vulnerabilidades.

Conforme abordagem de Wood (2011), perante os contextos de crise, o capitalismo - a exploração predatória - foi sempre apresentado como uma promessa de solucionar os problemas sociais com vistas à exclusividade econômica, conduzindo a humanidade para acumulação de riqueza e consequente prosperidade monetária, guiado pelos princípios da 'liberdade e autonomia individual', sob o pacto de que todos usufruirão dos frutos do sistema. No entanto, as leis de mercado, 'auto reguladoras', não se demonstraram suficientes para solucionar os problemas ligados a fome, a subnutrição, a miséria e enfim às mortes por mistanásia estrutural que levam à morte por vulnerabilidades. Segundo o autor:

O capitalismo, movido pela lógica do lucro, não há correspondência necessária entre capacidade produtiva e qualidade de vida humana. Uma sociedade com as mais avançadas forças produtivas, com capacidade para alimentar, vestir, abrigar, educar e tratar da saúde de sua população em grau que nem a mais visionária das utopias ousaria sonhar, pode, apesar de tudo ser castigada por pobreza, decadência, falta de moradias, analfabetismo e até doenças de desnutrição. (Wood, 2011, p. 126-127)

Por outro lado, da exploração predatória - capitalismo moderno - resultam as chagas e mazelas sociais que se consubstanciam em violações de direitos humanos e fundamentais, destruição de um meio ambiente ecologicamente equilibrado e a própria subversão dos valores econômicos. Costa (2019) enfatiza que, além da destruição a atual estrutura de exploração predatória tem impedido que pessoas, instituições e a própria ciência se manifeste, estude e aplique conhecimentos e técnicas que possam recuperar cenários degradados pela sede de poder, conforme

O 'sujeito-vítima' dessa reorganização de mundo pós-industrial e pós-escravagista, tornou-se um ser excluído para aquilo que se considera digno à vida, e mesmo em condições precárias, com direitos suprimidos, continua sendo o próprio alicerce de sustentação desse modelo exploratório, vendendo uma grande parte de sua vida às organizações que fazem história tornando-se centenárias, ricas e multinacionais com o aval do Estado (Costa, 2019, p. 124).

Se torna imperativo que a ética não era considerada nos estudos econômicos após Adam Smith (Cougo, 2016; Capita, 2021), desde o início da terceira década do século XXI, os consensos ligados ao desenvolvimento sustentável, à justiça e ao bem-estar social são ignoradas ou parcialmente aplicadas nas concepções de desenvolvimento econômico nacional, já que despender de tempo, recursos e pessoal para conformar as práticas produtivas aos consensos éticos representam relevante ônus para os interesses privados que se constituem em funcionamentos concorrenciais.

Recordemos que João Paulo II (2004, no 546) preconiza que os seres humanos não vivem duas vidas paralelas "por um lado, a vida chamada 'espiritual', com os seus valores e exigências, e, por outro, a chamada vida 'secular', ou seja, a vida da família, do trabalho, das relações sociais, do empenhamento político e da cultura", no entanto, diante das assimetrias econômicas, das desigualdades faces as capacidades em virtude de renda e dos impactos irreparáveis ao meio ambiente é possível afirmar que há um relevante distanciamento entre aquilo que é prescrito pelos valores econômicos e aquilo que é de fato realizado. Para Francisco (2015, no 95) "O meio ambiente é um bem coletivo, patrimônio de toda a humanidade e responsabilidade de todos. Quem possui uma parte é apenas para a administrar em benefício de todos".

À luz das 'vidas paralelas' recorda-se o termo dicotomia para observar que, "Não é suficiente compreender que os pobres do mundo precisam da globalização tanto quanto os ricos; também é importante garantir que eles de fato consigam aquilo de que necessitam. Isso pode exigir reforma institucional extensiva, mesmo quando se defende a globalização" (SEN, 2010, p. 24)

Nesse diapasão, ousa-se refletir sobre a vida e a vivência que aproxima e se reaproxima de temáticas sobre economia 
e ética, não como dimensões antagônicas, ao contrário, pela necessidade de compreender a unicidade que envolve os valores, os princípios, a economia e as demais dimensões que dialogam com a práxis para que se possa superar "as vidas paralelas" a que as pessoas estão inclinadas a viver, a destarte, a pergunta que fica é: porque a ética e a economia se distanciaram de tal forma, que criamos uma ética sem economia e uma economia sem ética?

\section{Metodologia}

O método utilizado para balizar a presente pesquisa é o dedutivo, que compreende a racionalização de ideias em sentido interpretativo utilizando-se da dedução, sendo este o raciocínio que parte do geral para o particular, conforme explicitado por Chizzotti (2017). Quanto à natureza, a pesquisa classifica-se como aplicada; quanto aos objetivos, exploratória; quanto ao método de abordagem, qualitativa e quanto aos procedimentos, trata-se de uma pesquisa bibliográfica, elaborada a partir de material publicado sobre o tema. Pode dizer que essa categoria de pesquisa consiste numa revisão bibliográfica ou levantamento bibliográfico e documental (Gil, 2017).

Assim, dada a natureza básica adotada, utilizou-se bibliográficas e documentos explorados pelos autores para embasar a narrativa-crítica que é produto deste estudo. O desenvolvimento da pesquisa está pautado na abordagem dialética, refletindo realidades em perspectivas aos conteúdos de determinado contexto social, as respostas qualitativas demonstram conceitos sobre um problema complexo e abrangente. A pesquisa objetiva respostas para a pergunta que justifica e norteia este estudo, qual seja: porque a ética e a economia se distanciaram de tal forma, que criamos uma ética sem economia e uma economia sem ética?

\section{Resultados e Discussão}

O agir humano é erigido mediante um conjunto que envolve necessidades, possibilidades e subsídios, a esta luz elucida-se conjuntos de valores morais com os quais se predispõe a práxis, englobando, definitivamente, a razão, a ética, a economicidade, a parentalidade e a sociabilidade enquanto formas de organização social. Os diferentes modelos e estruturação socioeconômicos que o ser humano propõe para viver em sociedade diz muito sobre a práxis - a sabedoria teórica que alimenta $\mathrm{o}$ agir das pessoas.

Superar os aspectos dicotômicos, promovendo a unicidade das dimensões, significa compreender as relações que estão intrinsecamente presentes, superar as percepções dicotômicas se faz necessários para que se possa pensar a práxis de economicidade em toda sua extensão ética. Aqui é saliente afirmar que o sistema econômico não pode anular a economicidade da pessoa, a destarte, um sistema econômico deve, em função de sua razão de existir, promover a economicidade humana em um ambiente ético, sustentável e global.

Dessa forma, a ética como arranjo sistemático de conhecimentos racionais e objetivos a respeito do comportamento humano moral volta-se para o agir humano na vida comum e real, nas ações individuais, nas atividades institucionais, na vida política e administrativa, portanto, nos locais onde é possível a materialização dos objetivos éticos estabelecidos (Vázquez, 1984).

\subsection{Afastamento entre ética e economia}

Os conhecimentos da ética são normalmente formulados e sistematizados a partir de esforços históricos de estudiosos, pesquisadores e teóricos. No entanto, a ética só se completa quando atinge os locais de convivência humana, à medida que se integra no agir e no administrar da realidade. Não haveria razão para fortalecer o conteúdo teórico da ética se esse não fosse aplicado nas atitudes dos indivíduos e instituições e consequentemente nas relações daí advindas. À esta perspectiva e sob uma 
concepção antropológica se deseja num primeiro momento refletir sobre o ser humano administrador, o homo administer.

Elucida-se que "as sociedades não são meros acidentes históricos, guarda-se por trás delas condições de vida e existência superiores àquelas encontradas em um estado de natureza" (Lovo et al, 2021, p.02), pois há um fim subjacente ao ordenamento social e aos sistemas sociais que o integram, que é a busca da felicidade humana condicionada pelas virtudes. Nessa linha, a ética ao lado de outras ciências sociais funciona como bússolas a apontar os caminhos ideais de se atingir os fins da convivência humana.

No entanto, a ética e as ciências econômicas nem sempre caminharam juntas no decorrer da história, pelo contrário, parte considerável do tempo essa relação foi de antagonismo, uma vez que a exploração, para ser predatória, precisa se contrapor à vivência ética, com isso se chega à alegação de incompatibilidade ou negação da ética. Para melhor compreensão da temática é necessário olhar para essa relação de desencontro entre as reflexões e análises éticas e as questões econômicas.

Até o século XVIII a economia, enquanto saber estruturado, era estudada nos campos da Filosofia Moral e em estudos teológicos (Kamphorst \& Zambam, 2014; Vaz, 2000) ao lado de conteúdos como Política, Jurisprudência Natural e Ética. Segundo Vaz (2000), nesse período a economia se voltava para os ensinamentos do usar e conservar com objetivos econômicos, mas era ao mesmo tempo altamente influenciada pelas concepções da ética aristotélica ao passo que tinha como objetivo o desenvolvimento de virtudes que são indispensáveis para a sociedade.

Nos séculos XVII e XVIII corroboraram para essa ordem de reflexão já que as concepções do direito natural vigente à época influenciavam todos os ramos do conhecimento, em especial as ciências morais, então, disciplinas como Economia e Política foram fortemente condicionadas pelo jusnaturalismo ${ }^{2}$, um conjunto de normas intersubjetivas e inerentes à condição humana, de conteúdo estreitamente ético, que se diferenciava das normas impostas pelo Estado. Acrescenta-se a isso que o desejo e a inclinação humana para viver em sociedade é Lei Fundamental do Direito Natural e é também a base e o fundamento da sociedade civil. Assim, nessa visão simultaneamente aristotélica e jusnaturalista, a economia e o comércio exercem função social de promover e reforçar os laços sociais objetivando multiplicar os benefícios para a sociedade (VAZ, 2000).

Nesse sentido, a busca da riqueza, tão somente pela riqueza, era vista como imoral, pois, a economia é a disciplina pela qual se ensina administrar e reger os recursos prudentemente. Para Lovo (2021, p. 13), "não é o que se tem, mas quantos vivem bem com o que se tem, sem que para isso outros tenham vivido, vivam ou venham a viver mal.", disso é possível extrair que a imoralidade não repousa na riqueza, o que realmente importa é a atitude que se pode ter diante do dinheiro e dos bens materiais e essa atitude passa a considerar que os bens são indiferentes e somente os usos que fazemos deles podem ser classificados como bons ou maus. Nessa perspectiva, os desejos de acumulação poderiam ser postos a serviço do bem comum (Vaz, 2000).

Cougo (2016) reforça que após Adam Smith, as ciências econômicas buscaram se afastar dos temas éticos em suas análises, objetivando construir teorias moralmente neutras e, quanto possível, puramente descritivas. Desta feita, segundo o autor, o economista ao estudar os fenômenos econômicos não deveria se preocupar com o bem-estar da sociedade do ponto de vista qualitativo, sendo função da economia, tão somente, encontrar os melhores meios para atingir fins econômicofinanceiros.

No entanto, surge nessa etapa de modernização da sociedade mercantil institutos econômico-jurídicos que decorrem da suplantação do modelo econômico feudal, que por sua vez permanecem relevantes posto que atemporais. No âmbito das relações privadas, há o fortalecimento da vontade individual e do poder de contratar, elementos necessários para a ideia de autonomia, que nessa fase da modernidade funda-se nos preceitos de legalidade. Nesse sentido, ninguém poderia ser obrigado 
a fazer ou deixar de fazer algo senão em decorrência da Lei, conforme veio a estabelecer oportunamente o art. $5^{\circ}$, inciso II, da Constituição Federal (BRASIL, 1988). Nesse contexto de fermentação econômica e ampliação dos mercados, os contratos privados passaram a ter a importante função de dotar os negócios de maior previsibilidade e segurança jurídica, sendo possível, em decorrência disso, que as partes requeiram coativamente as prestações pactuadas sob a égide do princípio e fórmula jurídica pacta sunt servanda.

É relevante ainda considerar que após as revoluções liberais, especialmente após a Revolução Francesa (1789), o processo de positivação do direito moderno é acentuado e permanece definindo o modus de atuação do direito contemporâneo. Neste cenário, é possível apontar que a pessoa deixa de observar, analisar e decidir - administrar seu próprio ambiente - para obedecer a Lei, se chega à máxima de que o que não é proibido pela Lei pode fazer.

O desenvolvimento do próprio mercado foi possível em virtude do fenômeno de codificação das leis civis que reunia os direitos e deveres dos cidadãos em suas relações privadas, uma vez que aquele exige segurança econômica e jurídica ${ }^{4} \mathrm{e}$ essas, por sua vez, são alcançadas pelo processo de positivação, de maneira que o Estado passa a ser o responsável pela solução dos conflitos sociais e aqueles que não foram resolvidos, em âmbito privado pelos próprios particulares.

No entanto, ao lado do progresso em diversos domínios do conhecimento, em especial ao avanço tecnológicoprodutivo, a modernidade criou caminhos em que a ética era assunto a ser tratado apenas na consciência individual - disso decorre uma ética sem economia -, pois as ciências nascentes não admitiam métodos que não fossem capazes de serem reproduzidos em qualquer local e que tivessem os mesmos resultados, salienta-se que a ética foge a essas exigências.

A produção e o mercado voltam-se para os fatores de otimização e maximização dos lucros individuais, como exigência do modelo capitalista, o que exige da economia constante aprimoramento da técnica - origem e fonte do tecnicismo. As despreocupações éticas subjacentes à modernização deixaram também, como legado, desigualdades econômicas, contradições de classe, explorações humanas e ambientais. Os caminhos antagônicos da ética e da economia tem feito com que a vivência humana se torne difícil, promovendo 'ilhas' de riquezas em decorrência da exploração, da vulnerabilizacão e da mistanásia que se instala nos ambientes 'não ilhados'. Para Costa (2019, p. 126), “contrariando qualquer justificativa, pode-se ousar a dizer que a economia é capaz de escolher aquele que come entre os que não comem. Aqueles que viverão mais e melhor daqueles que morrerão mais cedo em piores condições de vida".

Deste modo, após reconhecer o papel que a economia predatória impôs à modernização do conhecimento e das ciências, é imperativo que se reconheça que "os abusos são de imediato sentidos como distorções à ideia originária de igualdade" (Bittar, 2019, p.206). apara o autor, esta é vista como pilar dos modelos democráticos herdeiros das revoluções liberais. Em sequência, a industrialização, a globalização do comércio e o desejo de ganho foram decisivos para o fortalecimento da ideia de que o mercado sob a influência do capitalismo seria suficiente para levar a sociedade e seus membros para uma condição permanente de prosperidade.

Assim, constrói-se uma consciência de que embora a realidade em que se vive não tenha ótimas condições de vida, basta seguir firme, trabalhando duro, que o esforço será recompensado futuramente e/ou ainda uma internalização de culpa em caso de não atingir o 'sucesso financeiro' como consequência de falhas ou pouco comprometimento. No entanto, há que se enfatizar que nesse arranjo ideológico existe um equívoco que se evidencia ao longo das últimas décadas: não há uma ética intrínseca em um modelo econômico que pressupõe a radicalização do autointeresse em detrimento das reais capacidades individuais de satisfazer-se.

Como resultado do antagonismo da ética e das questões econômicas, a economia passou a se alicerçar em ideais de eficiência, exploração, pragmatismo, desenvolvimento do Produto Interno Bruto dos países, desenvolvimento de diversas

\footnotetext{
${ }^{3}$ Do latim: os pactos devem ser observados, cumpridos.

${ }^{4}$ Bittar, Eduardo C.B. Introdução ao Estudo do Direito: humanismo, democracia e justiça. (2019, p. 197)
} 
estratégias de competitividade e expansão das necessidades de ganho e acumulação de riquezas (Kamphorst \& Zambam, 2014).

Outrossim, pode-se captar que o elemento central do discurso do projeto capitalista reúne percepções de que "a face do poder nem sempre guarda a beleza de uma obra em grupo, pois, apesar de a plantação ser coletiva, a colheita quase sempre é individual, quando se refere a lógica do trabalho e ao capitalismo" (Costa, 2019, p. 121).

Pelo prisma de quem explora, a desigualdade se naturalizou pelo sistema econômico, culminando até mesmo com a sensação de culpa do próprio explorado quando não consegue responder às exigências produtivas.

A centralização do poder no capital - submissão ao produtivismo - e a possibilidade de acumulação infinita de riquezas fez com que o individualismo se tornasse método de funcionamento das atividades econômicas, e se tornou a própria razão de ser da via humana, a destarte, a ética que no passado delineava os limites dessas atividades é secundarizada e permanece, quando muito, no plano das declarações formais sem uma relevante materialização.

No entanto, os acontecimentos catastróficos do século XX, bem como as discussões políticas, éticas, filosóficas, sociais e jurídicas, resultantes de tais tensões, promoveram um reexame das finalidades das ciências e da razão humana. É após a quebra de expectativa diante da ciência e, a consequente percepção de que a técnica afastada dos valores éticos pode ser contraproducente é que se inauguram os debates em direitos humanos e a necessidade de recolocar em local de destaque o conteúdo ético.

Isto posto, cumpre observar que as várias facetas da ética têm pretensões de guiar as ações humanas para a satisfação comum e suscitam, em algum nível, a condição de agente solidário e fraterno como meio e fim para uma economia social, em perspectiva da pessoa humana ser protagonista de uma economicidade, de uma sociabilidade e de uma subsidiariedade que elevam o ser humano a desenvolver-se de forma sustentável.

\subsection{Fundamentos filosóficos da ética}

É possível intuir que para as doutrinas filosóficas representadas por Platão e Aristóteles, a felicidade ocupa espaço central em suas discussões éticas. Para o primeiro o sumo bem (felicidade) era conquistado quando o indivíduo incorpora em si, práticas de ações virtuosas e pela prática das virtudes o ser humano sábio se eleva do bem que pratica ao sumo bem. Já para o segundo, Aristóteles, a finalidade da vida humana era a busca da felicidade através da ética. Aristóteles (1979, p. 71) aponta que "pela prática de atos justos se gera o homem justo, e pela prática de atos temperantes; o homem temperante; sem essa prática, ninguém teria sequer a possibilidade de tornar-se bom", assim apresentando uma perspectiva daquilo que considera ético como sendo um conjunto de ações que conduz o homem ao senso de justiça o qual torna-o bom.

A ética aristotélica tem como ponto de partida uma abordagem teleológica, na qual tudo aquilo que existe tende para uma finalidade e o fim de todas as ações humanas é o bem soberano. Para o ser humano esse bem supremo é a felicidade, um fim em si mesmo por meio da qual não se busca nada além, pelo contrário, as demais ciências caminham para esse local em comum, pois o bem supremo a "felicidade" é "por si" e "por causa de si", o télos. Nesse sentido, para o autor, o indivíduo tem em si a potencialidade de realizar o bem e atingir o télos da existência humana. É mediante o cultivo de bons hábitos que se constrói a moralidade necessária à felicidade e a realização da sociedade nas virtudes (Kamphorst \& Zambam, 2014).

Por isso mesmo, no plano econômico as ações não devem estar desvinculadas da busca da felicidade geral e das concepções de virtude. Os ideais de virtude são alcançados mediante uma educação direcionada ao ser em sua essência, para que esse aprenda a encontrar o caminho de equilíbrio que promova a noção de família humana. Sugere-se, portanto, pensar o ser humano enquanto um administrador responsável, de modo geral é pensar o sentido antropológico do ser humano e descrevê-lo como o homo administer.

Pretende-se que os interesses individuais, egocêntricos, possam ser deslocados na direção dos interesses universais e 
sociais para que se chegue à mediana e o ponto de equilíbrio seja estabelecido. Desta forma, o ser humano não pode, em virtude de benefícios próprios e/ou parentais, comprometer o ambiente onde vive. Finalmente, as virtudes dadas pela natureza, são alcançadas pelo exercício e pelo hábito, a natureza humana é, por essência, dotada das potencialidades e capabilidades que precisam ser devidamente conceituadas e ensinadas para que cada pessoa possa desempenhar atitudes virtuosas e aperfeiçoalas com a prática, formando a práxis necessária para administrar a casa comum, de modo que "A escolha racional tem de exigir algo pelo menos com respeito à correspondência entre o que se tenta obter e como se busca obtê-lo" (Sen, 1999, p. 29).

Por outro lado, para Immanuel Kant a compreensão ética repousa no senso de dever e de agir mediante imperativos fornecidos pela razão de agir moralmente. O indivíduo dotado de razão desempenha sua autonomia na medida que encontra em si mesmo a práxis da moralidade e não por determinações heteronômicas ${ }^{5}$, de forma que nossa capacidade de pensar e raciocinar "nos transformam em algo mais do que meras criaturas com apetites" (Sandel, 2019, p. 140). O autor assevera ainda que se espera de seres racionais a possibilidade de que sejam educados e que se eduquem na busca de uma ética que suscite o elo dinâmico entre a responsabilidade e a autoridade.

Para Kant, os humanos não devem ser tratados como meros instrumentos para alcance das satisfações individuais ou serem vistos como meros meios que desempenham utilidades. Pelo contrário, humanos são dignos de si mesmos e são dotados de importância absoluta. Por isso, uma sociedade se realizará moralmente à medida que suas estruturas e instituições servirem aos critérios universais de dignidade humana, repousa à esta dignidade a responsabilidade do homo administer. Francisco (2020, $\mathrm{n}^{\mathrm{o}}$ 22) elucida que "Quando a dignidade do homem é respeitada e os seus direitos são reconhecidos e garantidos, florescem também a criatividade e a audácia, podendo a pessoa humana explanar suas inúmeras iniciativas a favor do bem comum."

Percorrendo tais visões filosóficas, embora de forma muito sintética, resta evidente que a utilidade da ética ultrapassa a função instrumental de avaliar os comportamentos humanos, já que exerce também a função de condicionar os atos da vida para a busca da felicidade, da realização e do bem-estar social. Pois, conforme kamphorst \& Zambam (2014), a ação humana, condicionada pela ética, ampara aspectos fundamentais da vida humana como a virtude e o dever.

Vivemos um mundo de opulência sem precedentes e, no entanto, esse mesmo mundo é atravessado por privações e desigualdades abissais que nos levam a concluir que as crises econômicas e sociais são também motivadas por crises éticas. Em sociedades marcadas pela desigualdade social, a debilidade ética serve para tornar ainda mais aguda a degradação da qualidade de vida das pessoas, a este respeito é ponderável que "Persistem hoje no mundo inúmeras formas de injustiça, alimentadas por visões antropológicas redutivas e por um modelo econômico fundado no lucro, que não hesita em explorar, descartar e até matar o homem" (Francisco, 2020, nº 22).

É possível, portanto, aferir que, para um desenvolvimento participativo e compartilhado se faz necessário avançar no sentido da compreensão antropológica, isto é, evidenciar uma cosmologia que possibilite imersão à práxis sobre a qual toda vida humana é chama a cultivar e guardar, isto é, administrar seu próprio ambiente sem para isso explorar outros ambientes.

\subsection{Assimetrias entre ética e economia}

O avanço tecnológico e o acúmulo de riquezas mundiais nos últimos 100 anos são extraordinários, vive-se num mundo de opulência sem precedentes (Sen, 2010). Contrariamente, os dados referentes a vida das pessoas não parecem acompanhar o vertiginoso desenvolvimento nas ciências tecno-produtivas, na agricultura e na área da saúde. Nesse sentido, uma relevante contradição se revela quando postas sobre o mesmo plano, simultaneamente, a função da economia, as potencialidades do planeta e a vida cotidiana marcada pela pobreza.

\footnotetext{
${ }^{5}$ Heteronomia é um conceito criado por Kant para denominar a sujeição do indivíduo à vontade de terceiros ou de uma coletividade. Se opõe assim ao conceito de autonomia onde o ente possui arbítrio e pode expressar sua vontade livremente
} 
Para Sen \& Kliksberg (2010) essas assimetrias e contradições tem a ver com a diminuta prioridade que é dada aos desfavorecidos e isso se revela em equívocos políticos e econômicos que lançam os pobres no pelotão de vulnerabilizados, piorando sensivelmente a situação quando se instala crises sanitárias, desastres da natureza.

É notório que o modo de viver, o mundo que criamos, se tornou um desastre para a natureza, um modo onde os seres humanos são levados a competir um com o outro, onde o outro - o próximo - é alguém do qual se pode levar 'vantagem', e a natureza é considerada como uma fonte inesgotável de recursos. A consciência ética pode ser abordada em duas instâncias genéricas: a primeira no plano individual que se manifesta na consciência e agir de cada pessoa e segunda no plano institucional, que se manifestam nas declarações e tratados universais, Constituições, ciências, códigos de atuação profissional e nos Estatutos das diversas organizações.

Sen (2011) avalia a sociedade à luz das capacidades, pois é por meio da capabilidade das pessoas para fazer coisas que elas têm razão para valorizar e que se julga a justiça e a injustiça na sociedade. Essa abordagem se concentra na vida humana e não em aspectos esparsos como renda, que na melhor das hipóteses são parte do caminho para o sucesso humano. Há, portanto, nessa abordagem "um sério deslocamento desde a concentração nos meios de vida até as oportunidades reais de vida" (SEN, 2011).

Em sua obra Desenvolvimento como liberdade, Sen (2010) buscou demonstrar que os principais problemas que afetam a humanidade no que se refere ao desenvolvimento não são, necessariamente, as rendas. Ele acredita que é mais adequado ver o processo de desenvolvimento como expansão das liberdades substantivas, que "dirige a atenção para os fins que o tornam importante, em vez de restringi-la a alguns dos meios" (2010. p. 16). Rendas individuais e Produto Nacional Bruto são meios relevantes que levam para o integral desenvolvimento humano, mas não devem ser encarados como um fim, pois os fins do desenvolvimento é a própria liberdade humana.

Francisco (2015, $\left.n^{\circ} 116\right)$, à luz da antropologia enfatiza que "a interpretação correta do conceito de ser humano como senhor do universo é entendê-lo no sentido de administrador responsável". Neste sentido, Lovo, (2020, p. 205) salienta que, "O convite ao ser humano para administrar a Criação, submete-o a tomar decisões de forma a desvendar o bem e o mal, em cada uma das situações que o impele a agir na Criação" e a despeito da capacidade do ser humano agir sugere que "sempre houve e haverá distância entre nossa capacidade de diagnosticar/planejar/prever e nossa capacidade de fazer/realizar/esperançar; tratase, pois, de um reino em desenvolvimento, portanto, contingente".

Nessa ordem de ideias, a expansão das liberdades reais das pessoas é considerada o fim primordial e principal meio de desenvolvimento. A reflexão sobre o papel constitutivo e papel instrumental. Constitutivo porque essas liberdades fazem parte da própria essência do desenvolvimento e instrumental pois elas também são úteis para perseguir o desenvolvimento que se deseja. As liberdades humanas são classificadas como fins de nosso desenvolvimento, a despeito de possuírem função instrumental, de modo que melhorar as condições de saúde e educação das pessoas certamente exerce uma função instrumental no incremento econômico, no entanto, devem ser encaradas sempre como constitutivas do desenvolvimento, ou seja, o próprio fim.

Destaca-se a produção rural familiar que visa a sustentabilidade para permanência das famílias no campo com dignidade, produzindo o necessário para a sua subsistência, respeitando as outras formas de vida, conforme destacam Leite et. al. (2021), segundo os quais "é essencial que a busca da sustentabilidade seja estabelecida mediante estratégias de transição agroecológica, visto que a agroecologia estima a vida humana e as demais formas de vida", sendo que a biodiversidade é sua condição intrínseca. Os autores defendem ainda que as monoculturas de grande escala são inaceitáveis, por destruírem as cadeias naturais que dão sustentação à própria vida.

É perceptível que essa abordagem é construtiva para a ética econômica pela diferenciação entre meios e fins. Os meios econômicos desempenham uma utilidade que só possui razão de existir quando caminha para os fins que é o 
reconhecimento da dignidade da vida humana. Nos escritos de Sen (2010), as instituições públicas e nacionais devem promover a ampliação de muitas outras liberdades substantivas ao lado da renda, como as liberdades individuais e políticas, facilidades econômicas, oportunidades sociais, transparência das instituições e seguridade social. Pois, conforme o mesmo, essas liberdades são elas mesmas os fins do desenvolvimento e não podem ser estabelecidas por meio de suas contribuições indiretas a outras características do desenvolvimento como o crescimento do Produto Nacional Bruto (PNB), haja vista que a liberdade é intrínseca à condição de ser humano.

No entanto, destaca-se que não é dispensável a função instrumental das liberdades no processo de desenvolvimento de modo que "a eficácia das liberdades como instrumento reside no fato de que diferentes tipos de liberdades apresentam interrelações entre si, e um tipo de liberdade pode contribuir imensamente para promover liberdades de outros tipos" (Sen, 2010, p. 10), pois, para Sen, essas liberdades apresentam uma relação de complementaridade elas estão empiricamente ligadas.

É interessante constatar que essa perspectiva de desenvolvimento é voltada para visão de agente, uma vez que em contextos em que as liberdades são garantidas as pessoas podem moldar seus próprios destinos e buscar ao seu próprio modo a felicidade. Há, portanto, uma importante valorização da condição de liberdade e agência humana, de forma que as pessoas devem ser sempre vistas como administradores de seu próprio ambiente. Por trás dessa perspectiva existe um forte endosso ético à medida em que a motivação implícita às capacidades é a superação do tecnicismo econômico que em pouco pode contribuir no uso e distribuição adequada dos recursos econômicos.

Destaca-se que a dignidade humana está devidamente condicionada pela forma como vivemos, em cenário onde a riqueza tem utilidade em si mesma e não na promoção do bem comum, na solidariedade e na subsidiariedade, se observa que a vida humana é desprezada para dar lugar ao acúmulo predatório de posses e cifras monetárias. É como se o desejo de posse tivesse que subtrair e vulnerabilizar ambientes, pessoas, culturas e famílias, para beneficiar outros ambientes, pessoas, culturas e famílias. Trata-se de construir ilhas de bondade e desenvolvimento às custas do empobrecimento e da exploração predatória de ambientes, movimentos como estes impossibilitam o ser humano de administrar seu próprio ambiente, vulnerabilizando e tornando-o submisso ao poder político.

A concepção subjacente ao desenvolvimento como expansão das liberdades com enfoque nas capacidades é a valorização da condição de agente das pessoas apresenta-se como fundamental para lidar com as diversas formas de privações. No entanto, a condição de agente é "inescapavelmente restrita e limitada pelas oportunidades sociais, políticas e econômicas de que dispomos" (Sen. 2010, p. 10). Em outras palavras, até mesmo a condição de agente e a própria liberdade individual necessita de comprometimento social, já que o grau e o alcance dessas liberdades são dependentes das forças sociais.

O humanismo reformulado e radicalizado pelas discussões filosóficas do século XX e amplamente divulgado por organizações internacionais transformou a temática da dignidade da pessoa humana em preocupação global, suscitou um arcabouço considerável de teorias e formulações que dizem respeito a direitos universais e humanos, essas teorias ainda se apresentam de forma dicotômica, é preciso superar "as vidas paralelas" da economia e da ética.

A concepção de vidas paralelas denuncia, em alguma medida, a precificação da essencialidade humana, não por sua realização natural, mas pela subcondição imposta por um projeto econômico em curso, segundo abordado por Costa (2019, p. 120), ao afirmar: "como é predominante o capitalismo não assume a ética como base de suas ações, mas a consubstancia num elemento de conveniência e de escolhas circunstanciais, assim, torna-se uma ética de mercado mesmo que em detrimento da condição humana". Ou seja, segundo sua percepção a condição humana percorre um caminho às margens da dignidade social e ainda assim impulsionando (consciente ou inconsciente) o funcionamento complexo deste projeto.

De fato, observa-se que um ambiente que é capaz de gerar ilhas de bondades, riquezas e benesses, tem seu contraponto no ambiente não ilhado, sendo preciso reformular a maneira como vivemos e isso passa intrinsecamente pela forma como pensamos a vida, a forma como pensamos as conquistas individuais e financeiras - a economia e a ética. Superar o 
enriquecimento em razão do empobrecimento é verdadeiramente romper com os conceitos éticos e filosóficos que predizem como devemos viver em sociedade. No plano institucional das declarações, dos direitos e das normativas legais há um consenso universal do valor intrínseco da pessoa humana, quer-se dizer que o ser humano já superou as fases em que buscava justificar a ética universal dos direitos humanos, passando, pois, para o desafio de efetivá-lo.

O caráter histórico dos direitos humanos atribui aos debates, princípios e valores indispensáveis para dado momento histórico, de tal modo que liberdade, autonomia, alteridade, desenvolvimento, identidade, responsabilidade e justiça social são assuntos frequentemente abordados no cenário nacional e internacional, que se vincula à necessidade de assistencialismo e subsidiariedade, ou seja, a distribuição de renda e garantia de condições mínimas de existência para pessoas vulnerabilizadas, pela exploração predatória, para que assim possam desenvolver suas capabilidades.

A concepção de justiça, de acordo com Sen (2010), foge da formulação de um modelo de justiça institucional transcendente, pois ele acredita que antes disso é mais importante que atenda às necessidades humanas reais. Lovo (2020, p. 212) corrobora ao afirmar que "O trabalho, quando desassociado da práxis de vida e vivência familiar, acaba por deixar o humano carente de relação, e consequentemente desenvolve a egolatria, o nacionalismo, e se finda em um individualismo hostil", de modo que para se falar de um desenvolvimento autêntico e real à vida humana é necessário. Na mesma linha, Sen (2010, p. 16 - 17) afirma: "Que se removam as principais fontes de privações de liberdade: pobreza e tirania, carência de oportunidades econômicas e destituição social sistemática, negligência dos serviços públicos e intolerância e interferência excessiva de Estados repressivos".

Compartilhando deste preceito, Costa (2019) aponta que o problema não está necessariamente no desenvolvimento econômico de uma nação ou de um povo, mas sim, na incapacidade do projeto capitalista de reversão desse 'suposto desenvolvimento' em condições de bem-estar social e potencialização das experiências da vida humana.

É necessário afastar-se do idealismo de que o desenvolvimento econômico é o suficiente para que provoque melhorias e equidade à vida humana, deixando de lado outros aspectos socialmente relevantes como os índices de desigualdade, de pobreza, de trabalho decente, de educação e sentido de pertença à família humana. Para a economista Sonia Rocha (2019), princípios democráticos e republicanos constantes na Constituição Federal de 1988, determinam que a assistência social seja reconhecida institucionalmente como um direito social, em oposição ao que ocorria, em que frequentemente o assistencialismo ficava a cargo de instituições filantrópicas.

O crescimento econômico nacional tem capacidades restritas de promover o bem-estar social universal, ele é dependente de fatores conjunturais como a ampliação do acesso a bens e direitos fundamentais, bem como de melhorias nas dinâmicas de distribuição e redistribuição dos rendimentos, pois, um país economicamente desenvolvido não será, necessariamente, um país humanamente desenvolvido (Rocha, 2019). Neste sentido, quando uma nação se estrutura de modo a aproveitar o desenvolvimento econômico para desenvolver as capabilidades das pessoas, terá como resultado pessoas capacitadas para administrar seus ambientes e não pessoas eternamente dependentes, essa é a diferença básica entre o assistencialismo e a subsidiariedade.

A transferência de renda entra como práxis de uma consciência ética, cordial e solidária de que os indivíduos necessitam de um mínimo para que sejam vistos como sujeitos e desempenhe a liberdade que lhe é própria, ao mesmo tempo que sejam criadas condições para que as pessoas possam desempenhar suas práxis cidadãs. Isso implica também, o mínimo para que possa ver as possibilidades pois a liberdade das pessoas, aqui considerada também a liberdade que a renda - bens, direitos, obrigações e sentido de pertença - promove, é parte constitutiva da ideia de desenvolvimento teorizada por Sen (2010) e adotada neste artigo. Segundo esta visão, as liberdades civis, políticas e sociais a despeito de terem uma função instrumental de promover o desenvolvimento econômico, elas possuem importância nelas mesmas de tal modo que devem ser valorizadas mesmo que não fossem capazes de interferir no incremento econômico de um país, pois são partes integrantes do conceito 
amplo e inclusivo de desenvolvimento.

Para Sen (2010), o mercado, enquanto lugar de troca e desempenho da autonomia individual, não é, por si só, a causa das desigualdades, das injustiças e dos abusos com o meio ambiente, ele passa a ocupar essa posição quando a economia e a acumulação de riqueza se transformam no objetivo de pessoas, instituições e nações. Sen (2010, p. 20) destaca ainda que "A contribuição do mecanismo de mercado para o crescimento econômico é obviamente importante, mas vem depois do reconhecimento da importância direta da liberdade de troca - de palavras, bens, presentes".

Segundo tal abordagem, é insuficiente que o valor humano seja reconhecido somente pelas declarações dos Estados nacionais, enquanto a política permanece vinculada aos interesses do mercado aético, criando, desta maneira, mais contradição na qual a ética seria suportada pelo Estado enquanto o mercado permaneceria perseguindo fins econômicos descompromissados com a humanidade. Na sequência, o autor descreve essa relação como patológica, pois, segundo o mesmo, o sistema econômico se sobrepõe ao sistema político, afetando até mesmo as relações democráticas ao afastar a ética de suas decisões ao mesmo tempo em que há o rapto de suas instituições para persecução do interesse privado. Para Sen (1999, p. 46), "As proposições típicas da moderna economia do bem-estar dependem de combinar comportamento autointeressado, de um lado, e julgar a realização social segundo algum critério fundamentado na utilidade, de outro".

Não se pode esperar que as instituições políticas sejam submetidas aos interesses da economia individualista e dessa relação resulte no desenvolvimento das capabilidades e liberdades. As necessidades humanas são urgentes e não podem esperar que espontaneamente sejam atendidas sem o exercício da função social do Estado e de suas políticas positivas de superação das privações de liberdades.

Desta forma, para Kamphorst \& Zambam (2014) o desenvolvimento como ampliação das capacidades é um modo de demonstrar que um norte engendrado pela ética pode alimentar mudanças significativas nas relações entre cidadãos e sociedades essas com o mercado, num processo ascendente de diminuição das desigualdades e consequentemente na construção de um ambiente propício para a vivência da libertação humana.

\section{Considerações Finais}

A liberdade humana não é alcançada com base na riqueza que se tem. Referida liberdade não é um fruto da ação humana, mesmo sendo profundamente afetada pela ação humana, ao passo que a liberdade, assim como a dignidade se concretizam à medida que as pessoas se realizam de modo social, uma vez que o ser humano é um ser social por natureza.

$\mathrm{O}$ fenômeno socioeconômico provocado pela propagação da pobreza e concentração da riqueza acaba por intensificar o sofrimento humano na medida que estreita as possibilidades de tecer políticas que assegurem a construção de sua dignidade e acesso ao bem-estar social.

O capitalismo provoca uma assimetria entre as experiências vivenciais à medida que, em um polo da relação se concentra a riqueza, noutro a pobreza de modo tão antagônico que a ética ocupa um plano secundário nas percepções de vida. Supostamente a vida passa ter um menor valor pela severa e descompassada relação socioeconômica, uma vez que dos pobres são tolhidos/limitados direitos essenciais à saúde, segurança, educação ou moradia.

$\mathrm{Na}$ perspectiva analítica afere-se que o capitalismo, em regra, não promove diálogo com a ética, haja vista que ocupando os mesmos arranjos sociais em diversos países, a dicotomia e o conflito (capitalismo x ética) é persistente. Neste prospecto se apresenta temas que devem ser observados em futuras pesquisas, isso porque, o exemplo do Brasil que, entre os países mais ricos do mundo tem uma população de famélicos e pessoas constantemente enquadradas no grupo de insegurança alimentar como afirma a Organização das Nações Unidas para Alimentação e Agricultura, em pesquisa publicada em $2021^{6}$.

${ }^{6}$ Pesquisa disponível em https://www.fao.org/family-farming/detail/fr/c/1392789/ 
Research, Society and Development, v. 11, n. 2, e53811226263, 2022

(CC BY 4.0) | ISSN 2525-3409 | DOI: http://dx.doi.org/10.33448/rsd-v11i2.26263

Ainda como pesquisas futuras se aponta que, diante da reflexão ora realizada, destaca-se que dos pobres é exigida a ética para não roubar, não se ausentar do trabalho, bem como uma subserviência disciplinar nas relações laborais, como uma questão de vigiar e punir em Foucault ${ }^{7}$. Sem a mesma disposição sobre a ética para garantir dignidade à pessoa em seu trabalho, mitigação das precariedades habitacionais, segurança alimentar. Logo, pode-se inferir a construção de uma pseudoética por conveniência do projeto capitalista o que contradiz qualquer perspectiva sobre uma ética social e humanitária.

\section{Referências}

Aristóteles. (1979). Metafísica: livro 1 e livro 2; Ética a Nicômaco; Poética. Seleção de textos de José Américo Motta Pessanha. Tradução de Vincenso Cocco et al. Abril Cultural.

Bittar, E. C. B. (2019). Introdução ao estudo do direito: Humanismo, democracia e justiça. (2 ed.). Saraiva.

Capita, F. L. (2021). A Decadência Da Relação Ética-Economia Como Fundamento Da Crise Econômica E Social Em Angola. Revista Científica Multidisciplinar Núcleo do Conhecimento. Ano 06, Ed. 03, 10, 100-22. ISSN: 2448-0959. https://www.nucleodoconhecimento.com.br/administracao/eticaeconomia

Chizzotti, A. (2017). Pesquisa em ciências humanas e sociais. (12. ed.). Cortez.

Costa, R. F. (2019). A ética na perspectiva da teoria das representações sociais e a filosofia da libertação. Fragmentos de Cultura, Goiânia, 29(1), 120-134. DOI: http://dx.doi.org/10.18224/frag.v29i1.6595

Cougo, F. F.. (2016). O enfoque das capacidades em Amartya Sen. Revista Enciclopédia de Filosofia, Pelotas, 5, 150-177. https://periodicos.ufpel.edu.br/ojs2/index.php/Enciclopedia/article/view/9349.

Francisco. Fratelli tutti. (2020) Roma: Libreria Editrice Vaticana. https://www.vatican.va/content/francesco/pt/encyclicals/documents/papafrancesco_20201003_enciclica-fratelli-tutti.html.

Francisco. (2015). Laudato Si’. Roma: Libreria Editrice Vaticana. http://w2.vatican.va/content/francesco/pt/encyclicals/documents/papafrancesco_20150524_enciclica-laudato-si.html.

Gil, A. C. (2017). Como Elaborar Projetos de Pesquisa. (6. ed.). Atlas.

João P. II. (2004). Compêndio da Doutrina Social da Igreja. Roma: Libreria Editrice Vaticana.

http://www.vatican.va/roman_curia/pontifical_councils/justpeace/documents/rc_pc_justpeace_doc_20060526_compendio-dott-soc_po.html.

Kamphorst, M. A.; Zambam, N. J. (2014). Ética e Economia: reflexões a partir de Amartya Sen. Clareira: Revista de Filosofia da Região Amazônica, v. 1, n. 2, p. 90-109. https://scholar.archive.org/work/huv3uiod2nbyhemvlbbviyerlm/access/wayback/http://www.revistaclareira.com.br: 80/index.php/ clareira/article/download/29/22.

Leite, E. S., Santos, A. C. M.., Freitas, C. O., Loose, C. E., \& Piacentini, M. T. S. (2021). Geração de Renda com Sustentabilidade para Permanência da Propriedade Rural Familiar: uma proposta agroecológica. International Journal of Development Research, 11(6), 48008-48013. DOI: https://doi.org/10.37118/ijdr.22121.06.2021.

Lovo, Odirlei Arcangelo. (2021). Administrar o reino ou a torre de Babel. RECIMA21 - Revista Científica Multidisciplinar - ISSN 2675-6218, [S. l.], 2(4), e24268. DOI: https://doi.org/10.47820/recima21.v2i4.268

Lovo, Odirlei Arcangelo. (2020). Potência da razão e as limitações do ato humano: ciência é esponsalidade com o Criador. Numen: revista de estudos e pesquisa da religião, Juiz de Fora, 23(2), 202-215. DOI: https://doi.org/10.34019/2236-6296.2020.v23.30874.

Lovo, Odirlei Arcangelo; Costa, Gustavo de Souza; Magro, Eleonice. de Fátima. Dal; Belete, Nícolas Alessandro de Souza. (2021). Razão e ética: práxis e governança global. Research, Society and Development, [S. l.], 10(16), e298101623817, 2021. DOI: https://doi.org/10.33448/rsd-v10i16.23817.

Rocha, Sonia. (2019). Transferência de Renda no Brasil: o fim da pobreza?. Alta Books.

Sandel, Michael J. (2019). Justiça: o que é fazer a coisa certa. 27. ed. Rio de Janeiro: Civilização Brasileira. Tradução: Heloísa Matias e Maria Alice Máximo Sen, Amartya. (1999). Sobre ética e economia. (L. T. Motta, Trad.), Companhia das Letras.

Sen, Amartya \& Klisberg, Bernardo. (2010). As pessoas em primeiro lugar: A ética do desenvolvimento e os problemas do mundo globalizado. (B. Ajzemberg, \& C. L. Silva, Trads.), Companhia das Letras.

Sen, Amartya. (2011). A ideia de justiça. Companhia das Letras.

Sen, Amartya. (2010). Desenvolvimento com liberdade. Companhia das Letras. Tradução: Laura Teixeira Motta.

Vaz, Francisco António Lourenço. (2000). Instrução e economia: as ideias económicas no discurso da ilustração portuguesa (1746-1820). 616 f. Tese (Doutorado) - Curso de História da Cultura Moderna e Contemporânea, Universidade de Évora, Évora. http://hdl.handle.net/10174/11228.

${ }^{7}$ Para um conhecimento mais profundo, faz-se a indicação da obra completa Vigiar e punir: Nascimento da prisão, Michel Foucault. Editora Vozes; $42^{\circ}$ edição (1 janeiro 2014). 
Research, Society and Development, v. 11, n. 2, e53811226263, 2022

(CC BY 4.0) | ISSN 2525-3409 | DOI: http://dx.doi.org/10.33448/rsd-v11i2.26263

Vázquez, A. S. (1984). Ética. Tradução de João Dell'Anna. (7. ed.). Civilização Brasileira.

Wood, Ellen Meiksins. (2011). Democracia contra o Capitalismo: a renovação do materialismo histórico. Boitempo. 